\title{
GAMBARAN STATUS GINGIVA PADA IBU HAMIL DI PUSKESMAS BAHU MANADO
}

\author{
${ }^{1}$ Gabrielle Warongan \\ ${ }^{2}$ Freddy Wagey \\ ${ }^{3}$ Christy Mintjelungan
}

\author{
${ }^{1}$ Kandidat Skripsi Program Studi Pendidikan Dokter Gigi Fakultas Kedokteran \\ Universitas Sam Ratulangi Manado \\ ${ }^{2}$ Program Studi Pendidikan DokterGigi Fakultas Kedokteran \\ Universitas Sam Ratulangi Manado \\ Email: gabriellewarongan@gmail.com
}

\begin{abstract}
Pregnancy is a unique period in a woman's life and is characterized by a complex physiological changes such as nausea and vomiting . These changes can affect oral health during pregnancy due to a change in diet and oral hygiene is lacking. Gingivitis is one that is highly susceptible to periodontal disease occurs when the maintenance of oral health in pregnant women is not properly maintained . The purpose of this study to describe the gingival status in pregnant women in health centers Shoulder Manado. This research is a descriptive cross sectional ( cross- sectional ). The study was conducted at the health center with research subjects Shoulder Manado as many as 34 people . By using the methods of sampling and measured Convecutive with gingival index by Loe and Sillness. The results showed that pregnant women in the second trimester is the average experience inflammation were a total of 11 people ( $79 \%$ ). And most pregnant women in the third trimester experienced severe inflammation as many as 16 people ( $80 \%$ ). The conclusion is that no one was found pregnant women with normal gingival status, which inflamed inflammation are 2 people with mild , 14 moderate and 18 people inflammation severe inflammation. Based on gestational age showed that pregnant women with gestational age Trimester III has a higher gingival index and describe more inflamed. For health centers are expected to further improve the program of oral health care of pregnant women such as promotional activities on the importance of health and oral hygiene during pregnancy, provide motivation and advice to pregnant women for health check to the dentist oral cavity simultaneously during pregnancy examination
\end{abstract}

Keywords: gingival status , pregnant women .

\begin{abstract}
Abstrak: Kehamilan adalah masa yang unik dalam kehidupan seorang wanita dan ditandai oleh perubahan fisiologis yang kompleks seperti mual dan muntah. Perubahan ini dapat memengaruhi kesehatan gigi dan mulut selama kehamilan yang disebabkan adanya perubahan pola makan dan kebersihan mulut yang kurang. Gingivitis merupakan salah satu penyakit periodontal yang sangat rentan terjadi jika pemeliharan kesehatan gigi dan mulut pada ibu hamil tidak terjaga dengan baik. Tujuan dari penelitian ini untuk mengetahui gambaran status gingiva pada ibu hamil di Puskesmas Bahu Manado. Penelitian ini merupakan penelitian deskriptif dengan pendekatan potong lintang (cross sectional study). Penelitian dilakukan di Puskesmas Bahu Manado dengan subjek penelitian sebanyak 34 orang. Dengan menggunakan metode Convecutive sampling dan diukur dengan indeks gingival menurut Loe and Sillness. Hasil penelitian menunjukkan bahwa ibu hamil pada Trimester II rata-rata mengalami inflamasi sedang berjumlah 11 orang (79\%). Dan kebanyakan ibu hamil pada Trimester III mengalami inflamasi berat sebanyak 16 orang (80\%). Kesimpulannya ialah tidak seorangpun ditemukan ibu hamil dengan status gingiva normal, dimana yang mengalami inflamasi terdapat 2 orang dengan inflamasi ringan, 14 orang inflamasi sedang dan 18 orang inflamasi berat. Berdasarkan usia kehamilan
\end{abstract}


menunjukkan, bahwa ibu hamil dengan usia kehamilan Trimester III memiliki indeks gingiva lebih tinggi dan menggambarkan lebih banyak mengalami inflamasi. Bagi Puskesmas diharapkan lebih meningkatkan program pelayanan kesehatan gigi dan mulut ibu hamil seperti kegiatan promotif tentang pentingnya menjaga kesehatan dan kebersihan mulut selama kehamilan, memberi motivasi dan nasehat kepada ibu hamil untuk memeriksakan kesehatan rongga mulutnya ke dokter gigi bersamaan pada saat pemeriksaan kehamilannya

Kata kunci: status gingiva, ibu hamil.

Kehamilan adalah masa yang unik dalam kehidupan seorang wanita dan ditandai oleh perubahan fisiologis yang kompleks seperti mual dan muntah. Perubahan ini dapat memengaruhi kesehatan gigi dan mulut selama kehamilan yang disebabkan adanya perubahan pola makan dan kebersihan mulut yang kurang. ${ }^{1}$

Walaupun pemeriksaan kehamilan (antenatal care) perlu dilakukan secara teratur dan berkala, tapi pemeriksaan gigi juga tidak boleh diabaikan. Pada kehamilan, terjadi peningkatan kadar asam di dalam rongga mulut, belum lagi jika wanita hamil mengalami mual dan muntah yang dapat mengakibatkan paparan asam lambung pada gigi dan gingiva. Hal ini dapat menyebabkan terjadinya radang atau penyakit gingiva, yang pada akhirnya bisa memengaruhi kehamilan dan perkembangan janin. $^{2}$

Gingiva ialah bagian dari mukosa mulut yang menutupi mahkota gigi yang tidak tumbuh dan mengelilingi leher gigi yang sudah tumbuh, berfungsi sebagai struktur penunjang untuk jaringan di dekatnya. Gingiva dibentuk oleh jaringan berwarna merah muda pucat yang melekat dengan kokoh pada tulang dan gigi, yang mukosa alveolar menyambung dengan mukogingival. $^{3}$

Gingivitis merupakan salah satu penyakit periodontal yang sangat rentan terjadi jika pemeliharaan kesehatan gigi dan mulut pada ibu hamil tidak terjaga dengan baik.Gingivitis adalah peradangan gingiva, menyebabkan perdarahan disertai pembengkakan, kemerahan, eksudat, dan perubahan kontur normal, Gingivitis sering terjadi dan bisa timbul kapan saja setelah timbulnya gigi, gingiva tampak merah. Peradangan pada gingiva dapat terjadi pada satu atau 2 gigi, tetapi juga dapat terjadi pada seluruh gigi. Gingiva menjadi mudah berdarah karena rangsangan yang kecil seperti saat menyikat gigi, atau bahkan tanpa rangsangan, pendarahan pada gingiva dapat terjadi kapan saja. ${ }^{4}$

Penyebab gingivitis pada saat kehamilan yaitu peningkatan konsentrasi hormon estrogen dan progesteron di dalam darah. Adanya perubahan hormonal disertai dengan perubahan vaskuler menyebabkan gingiva menjadi sensitif khususnya terhadap toksin maupun iritan lainnya, seperti plak dan kalkulus yang mengakibatkan gingiva mengalami peradangan.Keadaan ini ditandai dengan papila interdental yang memerah, bengkak, mudah berdarah dan disertai rasa sakit. ${ }^{5}$

Keparahan gingivitis memuncak pada usia kehamilan delapan bulan dan menurun pada usia kehamilan sembilan bulan, dengan pola akumulasi plak yang sama. Newman melaporkan tingkat keparahan gingivitis terbesar terjadi pada trimester kedua dan ketiga. Pengurangan tingkat keparahan gingivitis dapat terjadi setelah dua bulan pasca melahirkan dan setelah satu tahun kondisi gingiva dapat kembali normal, dapat dibandingkan dengan kondisi wanita yang tidak hamil. Namun, gingiva tidak akan kembali normal jika faktor lokal tidak dihilangkan. ${ }^{6}$

Di Indonesia, gingivitis menduduki urutan kedua yaitu mencapai 96,58\%. Berdasarkan Riset Kesehatan Dasar (RISKESDAS) pada tahun 2013, masalah gigi dan mulut termasuk penyakit pada gingiva di Provinsi Sulawesi Utara sebesar 31,6\%. Penelitian sebelumnya menunjukan prevalensi gingivitis sekitar 94,4\% dengan 63,97 tingkat keparahan ringan dan 30,6\% tingkat keparahan sedang. ${ }^{7}$

Puskesmas Bahu merupakan salah satu sarana pelayanan kesehatan masyarakat 
yang ada di kota Manado yang memberikan layanan preventif, promotif, kuratif dan rehabilitatif. Kebanyakan ibu hamil juga lebih rutin memeriksakan kehamilannya namun sering mengabaikan pemeriksaaan kesehatan gigi dan mulut. Sejauh ini penelitian tentang status gingiva pada ibu hamil belum pernah dilakukan di Puskesmas Bahu.

Berdasarkan hal-hal tersebut, maka penulis tertarik untuk melakukan penelitian mengenai gambaran status gingivapada ibu hamil di Puskesmas Bahu Manado.

\section{BAHAN DAN METODE PENELITIAN}

Penelitian ini merupakan penelitian deskriptif dengan pendekatan cross sectional study, yang dilaksanakan di Puskesmas Bahu Manado. Populasi dalam penelitian ini ialah ibu hamil Puskesmas Bahu Manado usia kandungan 4-9 bulan yang berjumlah 34 ibu hamil. Sampel penelitian diperoleh dengan metode consecutive sampling sesuai kriteria inklusi yang berjumlah 34 ibu hamil. Kriteria inklusi yaitu Ibu hamil yang tidak buta huruf, dapat berkomunikasi dengan baik, Ibu hamil dengan usia kehamilan 4-9 bulan (Trimester II-III). Kriteria eksklusi yaitu Ibu hamil yang memiliki riwayat penyakit sistemik seperti diabetes mellitus, ibu hamil yang menggunakan gigi tiruan, ibu hamil yang memakai alat ortodontik, ibu hamil yang kehilangan gigi indeks.

Instrumen yang digunakan dalam penelitian ini ialah formulir pemeriksaan. Alat dan bahan yang digunakan dalam penelitian ini ialah alat diagnostik, probe periodontal, masker dan sarung tangan, alkohol 70\%, dan air dan sabun cair antiseptik. Pengambilan data dilakukan dengan cara pemeriksaan klinis status gingiva pada ibu hamil. Data diolah dengan menggunakan program komputer Microsoft Office Excel 2010 dan disajikan dalam bentuk tabel distribusi frekuensi kemudian dianalisa berdasarkan hasil persentase.

\section{HASIL PENELITIAN}

\section{Karakteristik subjek penelitian}

Karakteristik sampel penelitian dilihat berdasarkan usia, usia kehamilan dan distribusi subjek penelitian status gingiva yang dijabarkan dalam Tabel 1-3:

Tabel 1. Distribusi sampel penelitian berdasarkan jenis kelamin

\begin{tabular}{ccc}
\hline Jenis kelamin & $\begin{array}{c}\text { Jumlahanak } \\
(\mathrm{n})\end{array}$ & $\begin{array}{c}\text { Persentase } \\
(\%)\end{array}$ \\
\hline $20-25$ & 13 & 38 \\
$26-30$ & 10 & 30 \\
$31-35$ & 10 & 30 \\
$36-40$ & 1 & 2 \\
\hline Total & 34 & 100 \\
\hline
\end{tabular}

Tabel 1 Jumlah ibu hamil yang berusia 2025 tahun sebanyak 13 orang (38\%) berusia 26-30 tahun sebanyak 10 orang (30\%) berusia 31-35 tahun sebanyak 10 orang (30\%) berusia 36-40 tahun sebanyak 1 orang $(2 \%)$.

Tabel 2. Distribusi sampel penelitian berdasarkan usia kehamilan

\begin{tabular}{ccc}
\hline $\begin{array}{c}\text { Usia } \\
\text { kehamilan }\end{array}$ & $\mathrm{n}$ & $\%$ \\
\hline Trimester II & 14 & 41 \\
Trimester III & 20 & 59 \\
Total & 34 & 100 \\
\hline
\end{tabular}

Tabel 2 Jumlah ibu hamil yang berada di Trimester II sebanyak 14 orang (41\%) berada di Trimester III sebanyak 20 orang (59\%).

\section{Hasil pemeriksaan status gingiva}

Hasil pemeriksaan status karies diperlihatkan dalam Tabel berikut:

Tabel 3. Distribusi sampel penelitian status gingiva

\begin{tabular}{ccccccc}
\hline \multirow{2}{*}{$\begin{array}{c}\text { Status } \\
\text { Gingiva }\end{array}$} & \multicolumn{5}{c}{ Usia kehamilan } \\
\cline { 2 - 7 } & \multicolumn{2}{c}{ Trimester } & \multicolumn{2}{l}{ Trimester } & Total \\
\cline { 2 - 7 } & $\mathrm{n}$ & $\%$ & $\mathrm{n}$ & $\%$ & $\mathrm{n}$ & $\%$ \\
\hline Sehat & 0 & 0 & 0 & 0 & 0 & 0 \\
Ringan & 1 & 50 & 1 & 50 & 2 & 100 \\
Sedang & 11 & 78,6 & 3 & 21,4 & 14 & 100 \\
Berat & 2 & 11,1 & 16 & 88,9 & 18 & 100 \\
Total & 14 & 41 & 20 & 59 & 34 & 100 \\
\hline
\end{tabular}


Tabel 3 Jumlah ibu hamil pada Trimester II yang mengalami inflamasi ringan yaitu 1 orang (7\%), inflamasi sedang sebanyak 11 orang (79\%), dan inflamasi berat sebanyak 2 orang (14\%). Jumlah ibu hamil pada Trimester III yang mengalami inflamasi ringan sebanyak 1 orang (5\%), inflamasi sedang sebanyak 3 orang (15\%), inflamasi berat sebanyak 16 orang (80\%).

\section{BAHASAN}

Sampel penelitian ini yaitu ibu hamil yang melakukan pemeriksaan kehamilan di Poli Kesehatan Ibu Anak Puskesmas Bahu.Hasil penelitian pada tabel 3 menunjukkan distribusi karakteristik sampel penelitian berdasarkan usia ibu hamil dengan kelompok usia terbanyak yaitu 20 sampai 25 tahun sebanyak 13 orang (38\%) dan paling sedikit kelompok usia 36 sampai 40 tahun yaitu 1 orang (2\%).Karakteristik sampel penelitian berdasarkan usia kehamilan menunjukkan Trimester III menempati jumlah terbanyak yaitu 20 orang (59\%).

Pemeriksaan klinis status gingiva pada ibu hamil diukur dengan indeks gingiva (Loe and Sillness) menggunakan probe periodontal. Dari hasil penelitian didapatkan bahwa tidak ada sampel penelitian dengan kategori gingiva sehat. Beberapa penelitian juga mendapatkan hasil yang sama. Nassrawin dkk, Ganesh dkk, Sarlati dkk, Yalcin dkk, dan Wander M dkk dalam penelitiannya juga tidak menemukan ibu hamil dengan status gingiva sehat. ${ }^{8,9,10,11}$

Faktor-faktor yang memengaruhi hal ini berupa perubahan hormonal yang terjadi pada masa kehamilankarena terjadi peningkatan respon terhadap plak sehingga terjadi penyakit gingiva.Selain itu kebersihan mulut yang buruk dari ibu hamil akan memperparah kondisi jaringan periodontal. ${ }^{12}$ Berbeda dengan hasil penelitian Hidayati dkk yang menunjukkan kehamilan itu sendiri tidak dapat menyebabkan gingivitis. Gingivitis pada kehamilan disebabkan oleh bakteri plak, sama halnya dengan gingivitis pada wanita yang tidak hamil. ${ }^{13}$
Tabel 5 menunjukkan distribusi status gingiva berdasarkan usia kehamilan pada ibu hamil Trimester II dengan kategori inflamasi sedang yang dominan. Pada Trimester III terjadi peningkatan inflamasi dengan kategori berat yang dominan. Selain itu, jumlah sampel yang mengalami inflamasi gingiva meningkat pada Trimester III. Hasil penelitian ini setara dengan penelitian dari Nassrawin dkk di King Hussein Medical Center Jordan yang menunjukkan pada Trimester III terjadi peningkatan jumlah sampel yang mengalami inflamasi gingiva yaitu mencapai $54,8 \% .{ }^{8}$ Penelitian ini juga didukung oleh hasil penelitian dari Wulan yang menunjukkan bahwa tedapat 8 orang (7,69\%) dengan usia kehamilan Trimester I, 17 orang (16,35\%) pada Trimester II sedangkan sampel penelitian pada Trimester III terdapat 79 orang(75,96\%).Terlihat perbedaan yang bermakna dalam presentase sampel pada usia kehamilan Trimester III yaitu 54,8\% pada penelitian dari Nassrawin dkk berbanding $75,96 \%$ pada penelitian dari Wulan dimana telah diketahui bahwa puncak terjadinya inflamasi berada pada Trimester III kehamilan. ${ }^{13}$ Berbeda dengan hasil penelitian dari Hidayati yaitu sebagian besar ibu hamil mengalami gingivitis sedang yaitu sebanyak $70 \%$. Sebanyak 18,6\% mengalami gingivitis berat dan sisanya sebanyak 11,4\% mengalami gingivitis ringan. ${ }^{14}$

Kehamilan dapat memperberat gingivitis yang biasa dikenal dengan pregnancy gingivitis atau radang gusi selama kehamilan, $^{15}$ yang merupakan respon inflamasi yang berlebih dari gingiva terhadap dental plak dan perubahan hormonal yang biasa terjadi selama masa kehamilan. Gejala klinis gingivitis ini mulai terlihat sejak bulan kedua dari kehamilan dan mencapai puncak pada bulan kedelapan. ${ }^{16}$ Penelitian ini setara dengan hasil penelitian yang dilakukan Noerdin menyatakan, pembengkakan yang terjadi pada gusi mencapai puncaknya pada bulan ketujuh dan kedelapan. ${ }^{17}$ Meskipun setelah kelahiran akan hilang dengan 
sendirinya tetapi tetap akan merupakan sumber peradangan bila kebersihan gigi dan mulut tidak terpelihara. Peningkatan hormon seksual terutama hormon progesteron dan estrogen pada masa kehamilan dapat menimbulkan perubahan pada rongga mulut berupa meningkatnya permeabilitas pembuluh darah gingiva sehingga menjadi sangatpeka terhadap iritasi lokal seperti plak, kalkulus dan karies. ${ }^{18}$

Selain masalah hormonal, penyebab utama gingivitis saat hamil adalah buruknya kebersihan mulut yang memudahkan terjadinya iritasi pada gingiva oleh enzim dan toksin bakteri anaerob yang terkandung dalam plak. ${ }^{19}$ Penelitian yang dilakukan Wardhani (2012) menunjukkan adanya hubungan antara tingkat kebersihan mulut ibu hamil dengan status gingiva nya yaitu semakin buruk tingkat kebersihan mulut ibu hamil maka semakin buruk juga status gingivanya. ${ }^{20} \mathrm{Hal}$ ini didukung oleh penelitian yang dilakukan oleh Hartati dkk (2011) yang mendapatkan ibu hamil dengan plak pada giginya lebih banyak mengalami gingivitis dibanding ibu dengan tidak ada plak pada giginya. ${ }^{21}$ Penelitian yang dilakukan oleh Rintoko (2005) juga menyatakan tingkat kebersihan mulut mempengaruhi terjadinya gingivitis pada ibu hamil. ${ }^{4}$

\section{SIMPULAN}

Status gingiva ibu hamil di puskesmas Bahu berdasarkan pengukuran indeks gingiva sebagian besar mengalami inflamasi dimana terdapat 2 orang dengan inflamasi ringan, 14 orang inflamasi sedang dan 18 orang inflamasi berat.

\section{SARAN}

Bagi Puskesmas diharapkan lebih meningkatkan program pelayanan kesehatan gigi dan mulut ibu hamil seperti kegiatan promotif tentang pentingnya menjaga kesehatan dan kebersihan mulut selama kehamilan, memberi motivasi dan nasehat kepada ibu hamil untuk memeriksakan kesehatan rongga mulutnya ke dokter gigi bersamaan pada saat pemeriksaan kehamilannya.

\section{DAFTAR PUSTAKA}

1. Mona.T.L,Krakowiak.P,Hujoel.P and Peters.M.R :Dental Care Use and Selfreported Dental Problems in Relation to Pregnancy.American.J.of Public Health 2004;94:5.765-70. 2.Jayanth K, Renee S, Ronald B, Howard M, Robert B, Ronald B, et al. Oral health care during pregnancy and early childhood: practice guidelines. NYS dep of Health [0824] Agustus 2006: [internet]. Diperolehdariwww.health.state.ny.us/p ublications/0824.pdf .

2. Adhi.2009. Kesehatan Gigi saatHamil. http://iwannabemom.com/2009/10/kese hatan -gigi-saat-hamil/.

3. Bloom, Fawcett DW. Buku Ajar Histologi. $12^{\text {th }}$ ed. Jakarta: EGC; 2002 p. 522.

4. Ubertalli, J.T. 2008. Gingivitis, Available at (online): http://www.merck.com/mmpe/sec08/ch 095c.htm (21 Agust 2010).

5. Ekaputri N, Sjahruddin FD. Hubungan perilaku wanita hamil dalam membersihkan gigi dan mulut dengan kedalaman poket periodontal selama masa kehamilan.Majalah Ilmiah Kedokteran Gigi 2005; 20 (62): h. 90 7.

6. Newman, A. 2006. Carranza's clinical periodontology. 10th ed. Philadelphia: WB.Saunders company.

7. Riset Kesehatan Dasar (RISKESDAS) 2013. Laporan Nasional. Kementerian Kesehatan Republik Indonesia; 2014. h.117.

8. Ganesh A, Ingle NA, Chaly PE, Reddy VC. A survey on dental knowledge and gingival health of pregnant women attending

government maternityhospital Chennai. Journal Oral Health Comm Dent 2011 ; 5 (1): p. 24-30.

9. Sarlati F, Akhondi N, Jahanbakhsh N. Effect of general health and sociocultural variables on periodontal status of pregnant women.

10. Yalcin F, Eskinasi E, Soydine M, Basegmez $\mathrm{C}$, Issever $\mathbf{H}$, Isik $\mathbf{G}$, Berber L, Has R, Sabuncu H, Onan U. The effect of 
sociocultural status on periodontal conditions in pregnancy.

11. Wander M, Engebretsen IMS, Okullo I, Tumwine JK, Astrom AN. Sociodemographic factors related to periodontal status and tooth loss of pregnant women in mbale district, Uganda, BMC Oral Health 2009, 9: 18: p. 1-11.

12. Hartati, et al. Analisis faktor-faktor yang berhubungan dengan kejadian gingivitis pada ibu hamil di wilayah kerja puskesmas talang tegal. Jurnal ilmiah kesehatan keperawatan. 2011. Vol 7 No 3: 170-189.

13. Wulan P. Gambaran status gingiva pada ibu hamil di BLU Prof. Kandou Manado. 2012. hal 26. SKRIPSI.

14. Hidayati. Prevalensi status gingiva pada ibu hamil di puskesmas Wonosobo. 2011. hal 28. SKRIPSI.

15. Retnoningrum, D. 2006. Gingivitis pada ibu hamil sebagai faktor resiko terjadnya bayi berat badan lahir rendah kurang bulan di rs. Kariadi Semarang. Dentika dental journal. Vol 1: 1-8.
16. Willmann, D.E., \& Nield- Gehrig, J.S. 2008. Foundation of Periodontics for the Dental Hygienist. Philadelphia: Lippicont Williams \& Wilkins.

17. Noerdin, S. 2001. Perawatan gigi pada ibu hamil. Dentika dental journal. Vol/pp: (6) : 49-56 Notoatmodjo,

18. Neville, B.W., Damm, D.D., \& White, D.K. 2003. Color atlas of clinical oral pathology. 2nd ed. USA: Medical Book.

19. Felton, Ann. 2009. Basic guide to oral health education and promotion. United Kingdom: Wiley-Blackwell.

20. Wardhani, Dika Fitria. 2012. Hubungan tingkat kebersihanrongga mulut dengan status gingiva pada ibu hamil di wilayah kerja puskesmas sumber sari kecamatan sumbersari kabupaten jember (penelitian observasional klinis). Skripsi Kedokteran Gigi. Jember : Universitas Jember.

21. Rintoko, Bimo. 2005. Kebersihan mempengaruhi adanya gingivitis pada ibu hamil. Dentika dental journal. Vol 1: $1-9$. 